\title{
BIM APPLICATION IN INFRASTRUCTURE PROJECTS
}

\author{
TATJANA VILUTIENE ${ }^{1}$, EDITA ŠARKIENE ${ }^{2 *}$, VAIDOTAS \\ ŠARKA ${ }^{3}$, ARVYDAS KIAULAKIS ${ }^{4}$ \\ ${ }^{1,4}$ Dept of Construction Management and Real Estate, Faculty of Civil \\ Engineering, Vilnius Gediminas Technical University, Vilnius, Lithuania \\ ${ }^{2}$ Dept of Roads, Faculty of Environmental Engineering, \\ Vilnius Gediminas Technical University, Vilnius, Lithuania \\ ${ }^{3}$ Dept of Engineering Graphics, Faculty of Fundamental Sciences, \\ Vilnius Gediminas Technical University, Vilnius, Lithuania
}

Received 20 February 2020; accepted 3 June 2020

\begin{abstract}
Building Information Modelling (BIM) is becoming a common language for the construction of buildings and infrastructure sectors worldwide. This paper aims at providing a broad picture of published journal papers on BIM application in infrastructure projects. The review is based on bibliometric analysis of 239 papers. The bibliometric analysis technique is used as the analysis method, which when compared to conventional literature reviews allows for the reduction in the likelihood of subjective judgments. The paper presents the review of BIM applications in infrastructure projects analysed within a 10-year period; the analysis of most recent studies and trends of applying BIM methodology identifies the gaps of BIM applications in infrastructure projects and defines future areas of research. Detailed analyses of citation networks present the co-occurrence map of keywords, citation
\end{abstract}

* Corresponding author. E-mail: edita.sarkiene@vgtu.lt

Tatjana VILUTIENÉ (ORCID ID 0000-0002-1617-8685)

Edita ŠARKIENE (ORCID ID 0000-0002-1608-1373)

Vaidotas ŠARKA (ORCID ID 0000-0001-8743-5266)

Arvydas KIAULAKIS (ORCID ID 0000-0003-3996-8070)

Copyright (C) 2020 The Author(s). Published by RTU Press

This is an Open Access article distributed under the terms of the Creative Commons Attribution License (http://creativecommons.org/licenses/by/4.0/), which permits unrestricted use,

distribution, and reproduction in any medium, provided the original author and source are credited. 
patterns of journals, articles and the most cited journals in the research area. Research shows that BIM applications in infrastructure projects have been continuously growing with a sudden increase after 2016. The study reveals that the research in this area conducted mainly in isolation comprised disjointed and fragmented research studies. Some of the sources are not available in scientific databases.

Keywords: Building Information Modelling (BIM), infraBIM, infrastructure, projects, review.

\section{Introduction}

Building construction and infrastructure sectors are strategically crucial to economies in terms of output, job creation and for the delivery and maintenance of the built environment. The European construction sector output is 1.3 th (trillion) EUR; it composes approximately $9 \%$ of the European GDP, and it employs over 18 million people. However, it is one of the least digitalised sectors with flat or falling productivity rates (EU BIM, 2017).

Infrastructure projects are complex, politically sensitive, and economically uncertain; they possess public versus private distributional issues and environmental considerations (Casady, Eriksson, Levitt, \& Scott, 2020). Therefore, smarter ways are needed to manage the challenges and create efficient infrastructures. As a decision, researchers propose digitalization, IoT and data analytics concepts, as well as ICT based smart solutions (Habibzadeh, Kaptan, Soyata, Kantarci, \& Boukerche, 2019; Kumar, Singh, Gupta, \& Madaan, 2020).

Recent research suggests that BIM can change the way AEC (Architecture, Engineering \& Construction) industries work (Dasović, Galić, \& Klanšek, 2019; Gholizadeh, Esmaeili, \& Goodrum, 2018). The analysis of studies on BIM applications shows that the benefits of using BIM in construction projects are still being explored (Galić et al., 2017; Vilutiene, Kalibatiene, Hosseini, Pellicer, \& Zavadskas, 2019). Although BIM-based work methods and technologies are implemented in construction companies, the efficiency of BIM application in projects has not yet been reliably evaluated (Ghaffarianhoseini et al., 2017). There is no unified system of criteria for this purpose and there is a lack of reliable evaluation methods (Sanchez, 2016; Succar \& Kassem, 2015). However, there is already a considerable body of evidence in the literature supporting BIM benefits in various areas throughout the AEC supply chain (Boton \& Forgues, 2018; Liu, van Nederveen, Wu, \& Hertogh, 2018).

BIM offers a variety of tools for designing, documenting, visualizing, and reporting, including software and information processing
BIM Application in Infrastructure Projects 
procedures. Such benefits add value to all supply chains at all stages of the building life cycle (Bradley, Li, Lark, \& Dunn, 2016; Hosseini, Maghrebi, Akbarnezhad, Martek, \& Arashpour, 2018). Specific BIM application benefits on the building operation phase are reported. A survey conducted by Williams, Haines, Roper, \& Yang (2019) revealed that integrating FM issues into the design process could help in selecting design decisions more effectively. BIM is becoming a common language for the building construction and infrastructure sectors worldwide and provides opportunities for more efficient collaboration. The survey conducted by Jones, Laquidara-Carr, Lorenz, Buckley, \& Barnett (2017) revealed that since 2015, there had been an increase in BIM methodology applications in infrastructure projects. Infrastructure projects have reported the following benefits of BIM methodology: shorter preparation of documentation processes ensures reproducibility, it is less errorprone, and there is the ability to assess the price and duration of the project accurately. The EU BIM TaskGroup, composed of public sector clients, infrastructure owners and policymakers from more than 20 European countries (EU BIM, 2017), predicts that BIM will become the global standard for implementing public infrastructure projects.

The present study contributes to the field in raising awareness of:

1) the knowledge of BIM applications in infrastructure projects analysed within the ten-year period;

2) most recent studies and trends of applying BIM methodology in infrastructure projects;

3) dominant categories of BIM-related benefits in infrastructure projects;

4) identifying gaps and future areas of research of BIM applications in infrastructure projects.

The remainder of the paper is structured as follows: the first section presents the methods used. The following section provides an overview of BIM applications in construction projects, potential benefits of BIM for the area of civil engineering, and followed by findings of BIM applications in infrastructure projects. Finally, the conclusions provide the discussion and the key findings, as well as suggestions for future research areas.

\section{Research methodology}

The research design for reviewing papers on BIM applications in infrastructure projects is displayed in Figure 1. The procedure begins with a brief review of published papers on BIM in Web of Science Core 
The research process, as illustrated in Figure 1, comprises the following steps.

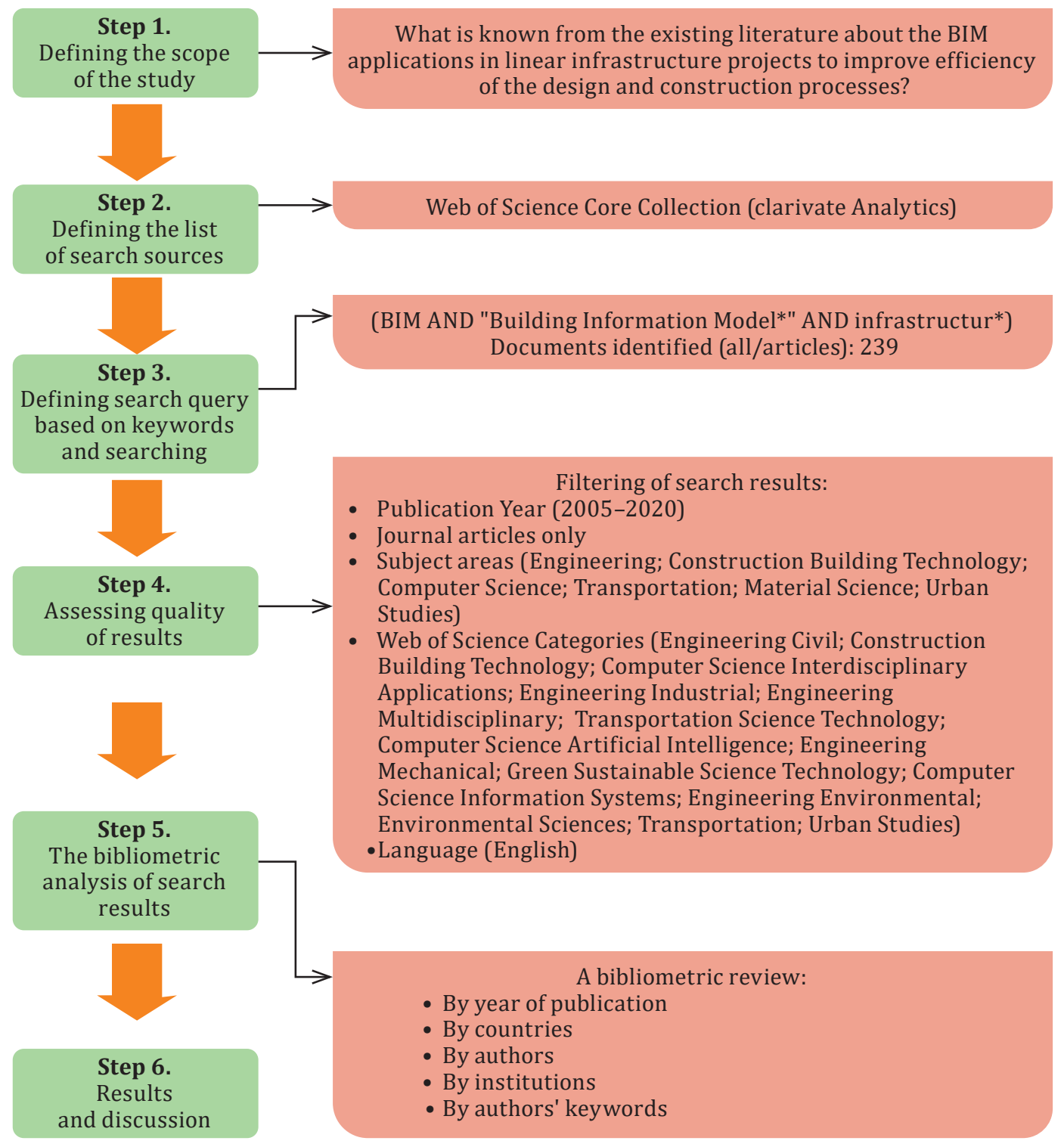

Figure 1. The research steps for a bibliometric analysis of the retrieved papers (created by the authors) 
Step 1. Defining the scope of the study and research question. This study was designed to examine the available journal articles and to determine the range of spreading and usage of BIM in infrastructure projects. The research question is "What is known from the existing literature about the applications of BIM methodology in infrastructure projects?"

Step 2. Defining the list of search sources. The Web of Science (WOS) Core Collection database was chosen. Compared to similar databases, WOS has reliable coverage starting from 1990 and most of its journals are in English.

Step 3. Defining search query based on keywords and searching. Searching keywords and their combinations defined using keywords: (BIM AND "Building Information Model*" AND infrastructur*). The searching is performed according to the query defined, and the preliminary results are presented in Figure 2.

Step 4. Assessing the quality of results. Quality of results was assessed by selecting only journal publications written in English, filtering of search by year of publication, by relevant subject areas, by referring Web of Science categories.

Step 5. The bibliometric analysis of search results. The bibliometric analysis technique is used as the analysis method, which is compared to conventional literature reviews, and it allows reducing the likelihood of subjective judgments. The findings of a bibliometric analysis are based solely on the reported data extracted from published datasets.

VOSviewer (http://www.vosviewer.com/) was used as the analysis tool for analysing, mapping, and visualisation of bibliometric data. VOSviewer generates a network from the given bibliographic data. All networks consist of nodes and links presenting articles, journals, authors, countries, organisations, or keywords. Nodes with a higher number of occurrences are more significant. Links present relationships among nodes. Thicker links present closer relationships among nodes. Carefully related nodes are combined into clusters using the smart local moving algorithm presented by Waltman and Van Eck (2013).

The first search results using the defined search query gave 239 documents. In Step 4 after filtering the search results by subject areas (Engineering; Construction Building Technology; Computer Science; Transportation; Material Science; Urban Studies) only 116 sources were found.

The search was refined by selecting the relevant Web of Science categories (Engineering Civil; Construction Building Technology; Computer Science Interdisciplinary Applications; Engineering Industrial; Engineering Multidisciplinary; Transportation Science Technology; Computer Science Artificial Intelligence; Engineering Mechanical; Green 


\section{Previous studies on BIM application in infrastructure projects}

In general, the projects of the built environment can be divided into two main categories: real estate projects and infrastructure projects. Infrastructure is defined as "the basic physical and organizational structures and means that are necessary for the operation of a society or enterprise" (Oxford Dictionary, n. d.). However, infrastructure can be divided into five main areas (Bradley et al., 2016):

- transportation infrastructure - roads, railways, bridges, tunnels and mass transit hubs (e.g., airports, ports);

- energy infrastructure - power generation plants (nuclear and wind farms), oil and gas (storage/distribution terminals, refineries and gas tanks) and mining;

- utility infrastructure - networks/pipelines for the delivery and removal of electricity, gas, water and sewage;

- recreational facilities infrastructure - parks and stadiums;

- environmental infrastructure - coastal defence management structures such as dams, levees or embankments.

Infrastructure often requires significant investment, so its rational use is expected to bring huge benefits to society (Damidavičius, Burinskienė \& Ušpalytė-Vitkūnienė, 2019). The vision for infrastructure upgrading and development of (digital) skills is one of the UK's National Priorities (Department for Business, Energy and Industrial Strategy, 2017). According to the UK report "Quantifying the Benefits of BIM", applying BIM to national infrastructure and construction projects could help bring to the economy about 430 million pounds per year (Quantifying the benefits of BIM).

Jones et al. (2017) report in "The Business Value of BIM for Infrastructure 2017" a graph that measures the growth of BIM deployment (for projects using BIM) for infrastructure projects. This report shows that the percentage of engineers and contractors working with BIM in the UK tripled between 2015 and 2019, respectively from $21 \%$ to $69 \%$.

Sanchez, Kraatz, Hampson, \& Loganathan (2014) indicate that the use of BIM at the early stages of infrastructure design would: 1) influence productivity gains; 2) allow for a comprehensive cost-benefit 
analysis leading to significant operating cost savings; 3) coordinate street and highway lighting planning concerning other energy and environmental aspects; 4) enable the measurement of key indicators, including long-term impact factors that could be transferred throughout the project life cycle; and 5) enable design documents to be integrated with sustainability objectives throughout their life cycle. According to experts, infrastructure projects provide better quality data than building projects (Krystallis, Papadonikolaki, Iuorio, \& Locatelli, 2019).

Yilmaz, Akcamete, \& Demirors (2019) proposed a BIM model for assessing the BIM maturity of building/infrastructure projects. However, it is more suitable for BIM maturity assessment of design practice, as four of its eleven measurement criteria - data volume, graphical information, 3D quality and information accuracy - are more closely related to design.

The review of Bradley et al. (2016) of BIM applications in the field of infrastructure and its use from a designer point of view highlights the growth of BIM applications in infrastructure projects. The analysis identified research gaps mainly related to information integration, compatibility of BIM processes with business processes, and (in)efficient information management.

Dell'Acqua, Guerra de Oliveira, \& Biancardo (2018) emphasised the importance of distinction between the use of BIM in building projects as "vertical BIM" and that used in infrastructure projects as "horizontal BIM". As organisations can participate in both construction projects and infrastructure projects, it is essential to understand the subtle levels of BIM applications in both cases. Horizontal (transportation) and vertical (buildings) construction has different operations, components and techniques from planning through construction, to operation and maintenance. Horizontal construction additionally relays on GIS data due to the length of the construction objects such as railway, roads, tunnels, etc.

The various benefits of applying the BIM methodology have been documented in building construction and infrastructure projects. Asl, Zarrinmehr, Bergin, \& Yan (2015) described how the modelling of energy consumption took place during the project design phase; many options were considered and although the optimization process was delayed, the developers managed to find the optimal most energyefficient option. The possibilities of providing energy savings with BIM are also mentioned by Abanda \& Byers (2016). Poirier, French, \& Forgues (2015) mentioned a 75\% increase in the productivity of design work among the advantages of using BIM. Opportunities to increase profits were mentioned by Lu, Won, \& Cheng (2016). The reduction in project design costs owing to the BIM methodology was mentioned by Love, Liu, 

\& Guo (2016). A project in Canada recorded that BIM application resulted in Infrastructure in rapid information transfer during design (McArthur, 2015). In another residential complex project in Canada, BIM succeeded in providing cheaper materials (Jalaei \& Jrade, 2015).

However, along with the benefits of using BIM, the studies mention various problems of BIM application. The Singapore project succeeded in ensuring material reuse, but the implementation of BIM in the project required additional costs (Akbarnezhad, Ong, \& Chandra, 2014). In Finland, the process of designing and constructing a multi-storey building succeeded in reducing risks owing to the use of BIM (Zhang et al., 2015). However, the authors of this study noted that the software used lacked modelling features.

BIM tools also succeeded in ensuring energy savings during the design and construction phases, but the most significant difficulty was with data exchange. Difficulties in data exchange were also mentioned by Lee, Oh, Lee, Hong, \& Jeong, (2015) and Poirier et al. (2015).

Mahamadu, Mahdjoubi, Booth, Manu, P. \& Manu, E. (2019) investigated the influence of BIM enablers on project success during the design and construction phases of 64 projects, including 56 building construction and other civil infrastructure projects. Their research revealed that BIM application ensures the accuracy of the information, better integration of design and construction processes, efficient collision analysis and the ability to analyse design alternatives and make rational decisions.

Yang, \& Chou (2019) analysed the application experience of BIM in the design, construction and operation phases of 13 different projects, including ten infrastructure projects (roads, bridges, sewage treatment plant, liquefied natural gas project, power distribution lines, power transforming station, wharf engineering) and projects of three buildings (museum, hospital, sport centre). Exploratory indicators were: clarity of design solutions, number of conflicts, quality of work, control/cost predictability, change requests, negotiation cycles. The study found that BIM resulted in $38.5 \%$ improvement in quality, $38.5 \%$ reduction in conflict, $61.5 \%$ clearer design, $23.1 \%$ reduction in modifications and $30.8 \%$ more accurate cost estimates. The authors of the study conclude that while there are a number of BIM benefit studies, there is a need for more precise quantitative methods for measuring the benefits of BIM as an alternative to the traditional methods currently used.

From the above, it can be concluded that most of the benefits of BIM come from the design stage. Specifically, energy modelling at the design stage is the most popular application of BIM in projects. The most commonly reported benefits of BIM are productivity improvements, 
time savings in design, and the most common issues are data exchange. Organisations starting to apply BIM and willing to measure the benefits of BIM for justification of their planned investments in this area compare the performance of completed and ongoing BIM projects. Companies experienced in BIM look at ongoing and completed BIM projects to evaluate BIM benefits, but with a slightly different goal, developing a more sophisticated approach of BIM in new projects, such as identification of the best configuration of the structure at the early stages of the project lifecycle (e.g., conceptual design), in combination with site limiting factors as well as cost optimization. Alternatively, at the concept phase, life cycle analysis (LCA) of alternative solutions and energy modelling are performed to identify the least polluting and energy-efficient solutions. It has also been found that the application of BIM methodology in building construction projects is more widely described, and so far, fewer publications have described the application of BIM methodology in infrastructure projects.

\section{Results}

\subsection{Trend of research}

The number of publications on BIM applications in infrastructure projects has increased significantly from 2012 onwards, as illustrated in Figure 2. This increase from 2012 may be related to the UK Government's Construction Strategy 2011 that requires mandatory application of BIM to all public sector projects at the second BIM maturity level by 2016 (Cabinet Office U.K., 2011). There is a growing interest, and the growth of publications acknowledges the need for further research in this area.

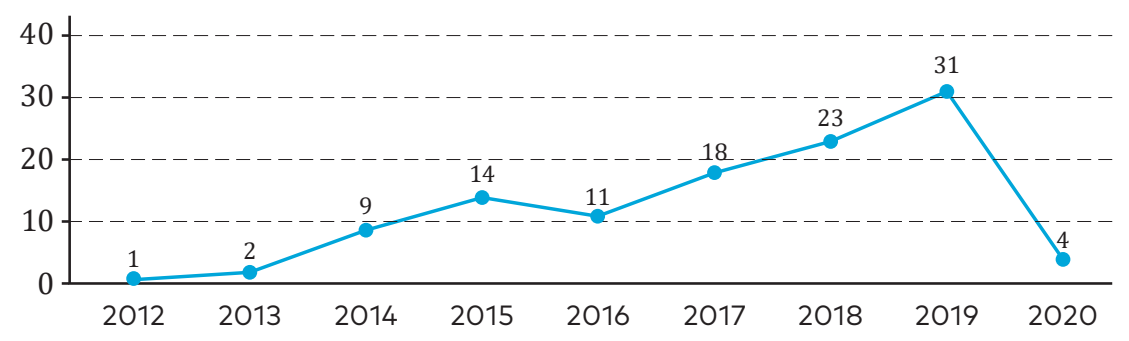

Figure 2. The research steps for a bibliometric analysis of the retrieved papers (created by the authors) 


\subsection{Co-authorship networks}

The analysis of co-authorship networks allows identifying the collaboration networks on a topic, stimulating the scientific communications and reducing isolated research. Table 1 introduces the top 20 organisations that have published more than two papers. As can be seen, the four most active organisations are Curtin University (9 articles), the University of Cambridge (5 articles), Ruhr University Bochum ( 4 articles), Tongji University (4 articles). The results of the literature analysis discussed above and the co-authorship network of countries are presented below.

Table 1. The most active organisations, where the number of articles exceeds or equals 3

\begin{tabular}{lcc}
\hline \multicolumn{1}{c}{ Organisations } & Number of articles & \% of 113 \\
\hline Curtin University & 9 & $7.97 \%$ \\
University of Cambridge & 5 & $4.43 \%$ \\
Ruhr University Bochum & 4 & $3.54 \%$ \\
Tongji University & 4 & $3.54 \%$ \\
Cardiff University & 3 & $2.66 \%$ \\
Concordia University Canada & 3 & $2.66 \%$ \\
National Taiwan University & 3 & $2.66 \%$ \\
State University System of Florida & 3 & $2.66 \%$ \\
Technical University of Munich & 3 & $2.66 \%$ \\
University of Florida & 3 & $2.66 \%$ \\
University of Twente & 3 & $2.66 \%$ \\
University System of Georgia & 3 & $2.66 \%$ \\
\hline
\end{tabular}

A co-authorship network of authors is generated from the core dataset. In Figure 3, the condition of a minimum number of two documents per country was set. After applying VOSviewer algorithms, of the 32 countries, 19 meet the threshold. An analysis of BIM research in infrastructure projects published over the last decade revealed that most papers had been published by researchers from the Peoples Republic of China, the USA, Germany, the United Kingdom, Australia, Canada, the Netherlands, Ireland, South Korea and Taiwan (Table 2). However, this analysis only partially reflects the state of BIM application in infrastructure projects. Some of the developments are not presented in journal articles, they are not included in the WOS database, but they describe advanced aspects of BIM application in infrastructure projects, 
methodologies, guides, employer information requirements and case studies. Some European countries with advanced BIM technologies have overlooked the importance of conducting and publishing research to facilitate and expedite the permeation of BIM in infrastructure projects. Meanwhile, many other sources discuss the BIM advancements in infrastructure projects, for example, the specification for the exchange of infrastructure information presented by BuildingSmart Finland (2017), practical requirements for classification of information in digital engineering presented in the study of Jackson (2019) requested by BuildingSmart Nordic.

Table 2. The most active countries, where the number of articles exceeds or equals 4 (WOS, January 2020)

\begin{tabular}{lcc}
\hline \multicolumn{1}{c}{ Countries/Regions } & Number of articles & \% of $\mathbf{1 1 3}$ \\
\hline Peoples R China & 20 & $17.70 \%$ \\
The USA & 20 & $17.70 \%$ \\
Germany & 19 & $16.81 \%$ \\
England (the United Kingdom) & 17 & $15.04 \%$ \\
Australia & 13 & $11.50 \%$ \\
Canada & 10 & $8.85 \%$ \\
The Netherlands & 7 & $6.20 \%$ \\
Ireland & 4 & $3.54 \%$ \\
South Korea & 4 & $3.54 \%$ \\
Taiwan & 4 & $3.54 \%$ \\
\hline
\end{tabular}

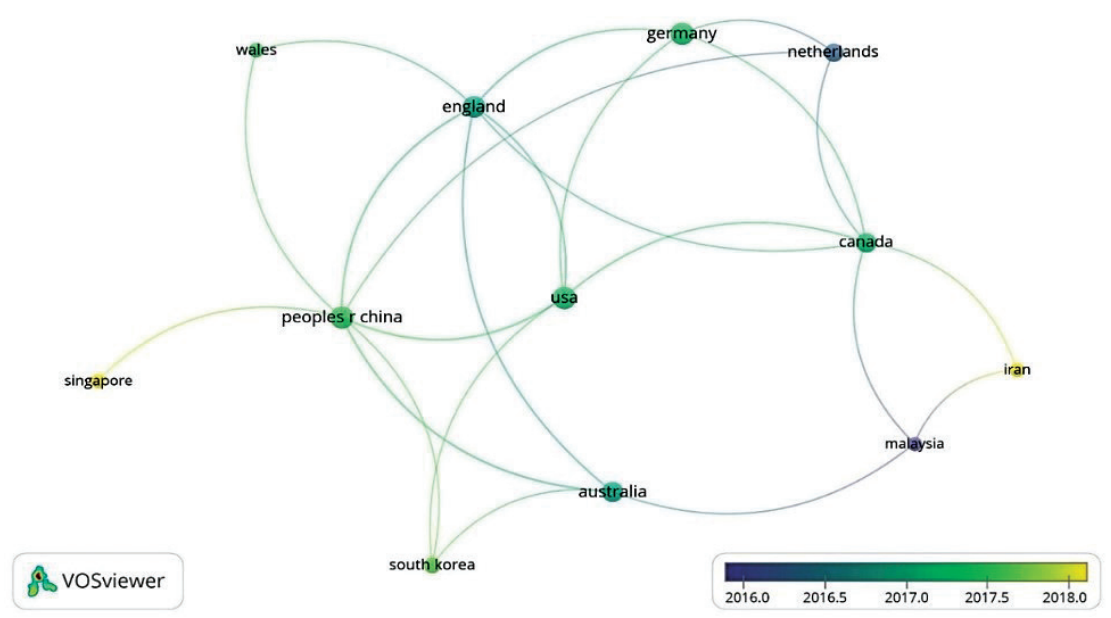

Figure 3. Co-authorship network of countries 
Table 3. The journals, where the number of articles exceeds and equals 2 (most often published papers on the research topic)

\begin{tabular}{lcc}
\hline \multicolumn{1}{c}{ Source titles } & Number of articles & \% of $\mathbf{1 1 3}$ \\
\hline Automation in Construction & 23 & $20.35 \%$ \\
Bautechnik & 10 & $8.85 \%$ \\
Engineering Construction and & 8 & $7.08 \%$ \\
Architectural Management & & \\
Journal of Computing in Civil Engineering & 6 & $5.31 \%$ \\
Buildings & 5 & $4.43 \%$ \\
\hline
\end{tabular}

Table 3 introduces the top journals that have published more than five papers on the research topic. As can be seen, the five most active journals are Automation in Construction (23 articles), Bautechnik (10 articles), Engineering Construction and Architectural Management (8 articles), Journal of Computing in Civil Engineering (6 articles), and Buildings (5 articles).

The analysis revealed that authors publishing papers on the topic of BIM in infrastructure projects worked mainly in isolated groups. The most cited articles in last ten years on the discussed topic of BIM in infrastructure projects were published by: Volk, Stengel, \& Schultmann (2014) with the number of citations being 490 and the number citations per year being 70 on average; Bradley et al. (2016) with the number of citations being 50 and ten citations per year on average; Shou, Wang, J., Wang, X., \& Chong (2015) with the number of citations being 38 and 6.33 citations per year on average; Chong, Lopez, Wang, J., Wang, X., \& Zhao (2016) with the number of citations being 23 and 4.60 citations per year on average; Cheng, Lu \& Deng (2016) with the number of citations being 23 and 4.60 citations per year on average; Marzouk \& Hisham (2014) with the number of citations being 17 and 2.43 citations per year on average; Costin, Adibfar, Hu \& Chen (2018) with the number of citations being 13 and 4.33 citations per year on average; Fanning, Clevenger, Ozbek, \& Mahmoud (2015) with the number of citations being 12 and two citations per year on average.

\subsection{Co-occurrence network}

The co-occurrence analysis is used to provide a picture of a domain, central areas of research and trends of development. This type of analysis is usually performed using keywords or terms to present the main content of articles and the range of researched areas in any domain of study. The co-occurrence analysis of terms was performed extracting 
terms from titles and abstracts. VOSviewer creates the network of terms using a binary counting method by considering the closeness and strength of existing links. In this study, the minimum number of occurrences of a term was 10 . Of the 3482 terms, 45 meet this threshold.

For each of the 45 items, VOSviewer algorithms calculated a relevance score. Based on this score, the most relevant terms were selected. The default choice was to select 60 per cent of most relevant terms. In this case, the number of terms selected was 27 . Those 27 terms composed four clusters as follows:

- the first cluster: "application", "BIM", "building", "building information model", "framework", "infrastructure", "integration", "level", "model", "operation", "system";

- the second cluster: "building information modelling", "design methodology approach", "development", "industry", "information modelling", "infrastructure project", "order", "project", "study", "way";

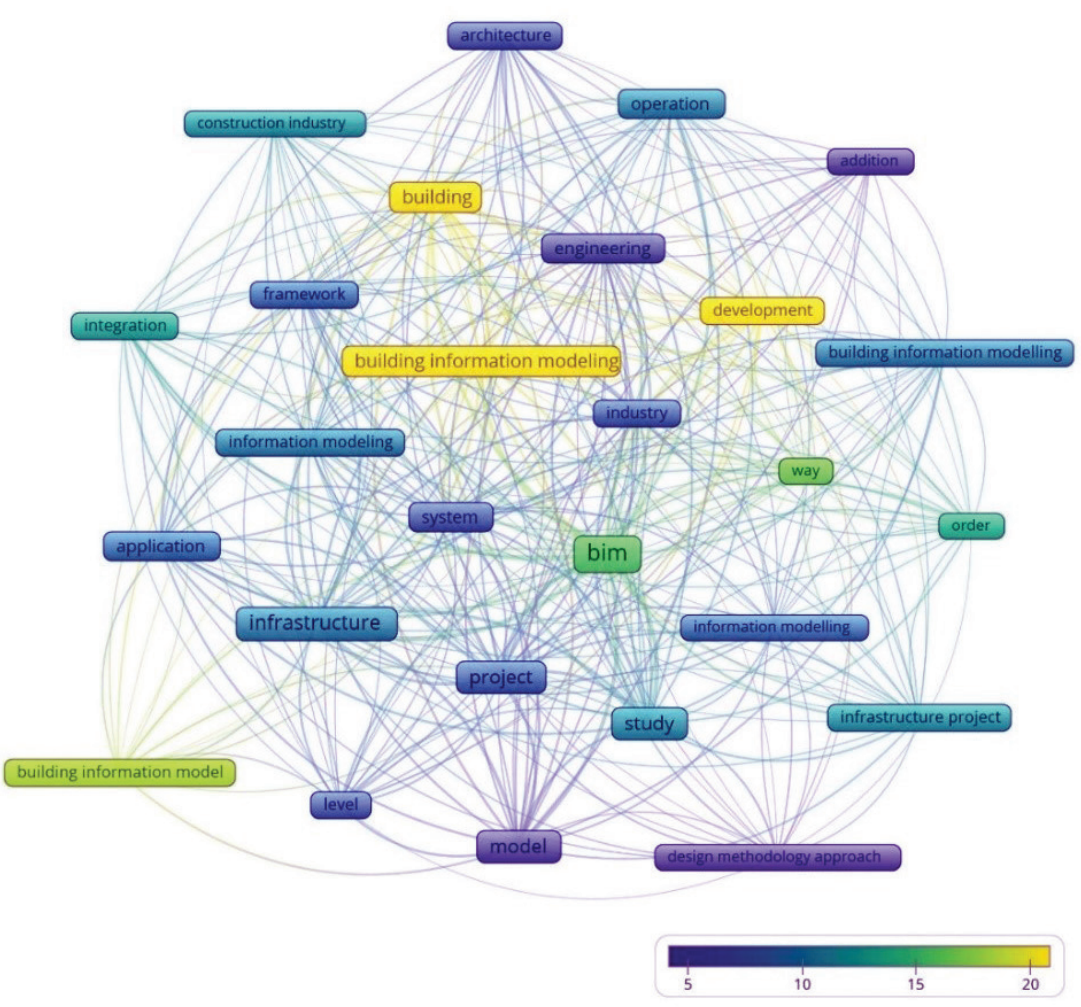

Figure 4. Co-occurrence map of terms by average citation 
- the third cluster: "architecture", "building information modelling", "construction industry", "engineering";

- the fourth cluster: "addition", "information modelling".

As can be seen from Figure 4, the map of terms is visualized using various colours to show the average citation of items. The most cited terms (coloured in yellow, green and light blue) are "building information modelling", "building", "development", "infrastructure", "infrastructure project”, "BIM", “way”, "operation”, "order”, "integration”, and "construction industry".

\section{Conclusions}

Rapid technological advances and fierce competition in the construction market for better quality services are driving a significant shift in the way construction projects are developed and implemented in the construction sector. The process of digitising construction processes is accelerating as an opportunity to change traditional practices and apply new ways of carrying out construction projects. BIM is currently considered the most innovative method in the entire construction industry. Despite significant improvements in BIM-related processes, it is still underutilised, mainly due to the need for significant changes in supply chains, as well as the risks and challenges of this change. Thus, research in the field of BIM is mainly dealing with general issues of integrating BIM into the infrastructure design and construction, removing common barriers to implementation of BIM in projects.

AEC industry stakeholders are facing similar problems with BIM implementation in infrastructure projects. The most frequently mentioned problems are difficulties in data exchange, data losses, and the justification for investments in IT systems and lack of modelling features.

The research revealed that the number of publications on BIM applications in infrastructure projects had increased significantly from 2012 onwards and the growth of publications acknowledged the need for further research in this area. The analysis also revealed that authors publishing papers on the topic of BIM in infrastructure projects worked mainly in isolated groups. Further research is needed through the formation of research networks of cooperation, in which intensifying dialogue, debate and mutual exchange of initiatives and ideas will be a priority.

The literature reviewed shows that today BIM is much better documented, understood and used in the building construction sectors compared to infrastructure. BIM has been lagging in infrastructure for 
several years, but this type of project is also well suited for model-based BIM deployment. However, proponents of BIM in the infrastructure sector believe that "stand-alone" BIM infrastructure projects have been going on for some time without being published in the scientific journals. This leads to the conclusion that promoters of projects should be encouraged to publish their research results more actively in the scientific literature to raise the visibility of the BIM advancements integrated into infrastructure projects.

Despite the contribution, the study has limitations. First, the analysis covered only literature in English. Secondly, the analysis is based on a set of data obtained from the Web of Science database, therefore, affecting the limitations of the coverage of analysis. Thus, the results may not fully reflect all available literature on BIM application in infrastructure projects. In addition, the study, due to limitations of space, was focused on providing a broad picture of the available BIM literature for infrastructure projects through a bibliometric analysis of citation networks and to a lesser extent related to an in-depth analysis of the content of available studies. Nevertheless, before the bibliometric analysis, the authors conducted an in-depth qualitative analysis of the articles.

\section{REFERENCES}

Abanda, F. H., \& Byers, L. (2016). An Investigation of the Impact of Building Orientation On Energy Consumption in a Domestic Building Using Emerging BIM (Building Information Modelling). Energy, 97, 517-527.

https://doi.org/10.1016/j.energy.2015.12.135

Akbarnezhad, A., Ong, K. C. G., \& Chandra, L. R. (2014). Economic and Environmental Assessment of Deconstruction Strategies Using Building Information Modeling. Automation in Construction, 37, 131-144. https://doi.org/10.1016/j.autcon.2013.10.017

Asl, M. R., Zarrinmehr, S., Bergin, M., \& Yan, W. (2015). BPOpt: A Framework for BIM - Based Performance Optimization. Energy and Buildings, 108, 401-412. https://doi.org/10.1016/j.enbuild.2015.09.011

Boton, C., \& Forgues, D. (2018). Practices and Processes in BIM Projects: An Exploratory Case Study. Advances in Civil Engineering, 12, 1-12. https://doi.org/10.1155/2018/7259659

Bradley, A., Li, H., Lark, R., \& Dunn, S. (2016). BIM for Infrastructure: An Overall Review and Constructor Perspective. Automation in Construction, 71, 139-152. https://doi.org/10.1016/j.autcon.2016.08.019

BuildingSmart Finland. (2017). Finnish Inframodel Application Documentation for LandXML v1.2. Version 4. [Online]. Retrieved from https://buildingsmart.fi/infra/inframodel/ [Accessed 25 November 2019]. 
Cabinet Office, U.K. (2011). Government Construction Strategy. [Online]. Retrieved from https://assets.publishing.service.gov.uk/government/ uploads/system/uploads/attachment_data/file/61152/Government-Construction-Strategy_0.pdf [Accessed 19 November 2019].

Casady, C. B., Eriksson, K., Levitt, R. E., \& Scott, W. R. (2020). (Re)Defining Public-Private Partnerships (PPPs) in the New Public Governance (NPG) Paradigm: An Institutional Maturity Perspective. Public Management Review, 22(2), 161-183. https://doi.org/10.1080/14719037.2019.1577909

Cheng, J. C., Lu, Q., \& Deng, Y. (2016). Analytical Review and Evaluation of Civil Information Modeling. Automation in Construction, 67, 31-47. https://doi.org/10.1016/j.autcon.2016.02.006

Chong, H. Y., Lopez, R., Wang, J., Wang, X., \& Zhao, Z. (2016). Comparative Analysis on the Adoption and Use of BIM in Road Infrastructure Projects. Journal of Management in Engineering, 32(6), 05016021. https://doi.org/10.1061/(asce)me.1943-5479.0000460

Costin, A., Adibfar, A., Hu, H., \& Chen, S. S. (2018). Building Information Modeling (BIM) for Transportation Infrastructure-Literature Review, Applications, Challenges, and Recommendations. Automation in Construction, 94, 257-281. https://doi.org/10.1016/j.autcon.2018.07.001

Damidavičius, J., Burinskienė, M., \& Ušpalytė-Vitkūnienė, R. (2019). A Monitoring System for Sustainable Urban Mobility Plans. The Baltic Journal of Road and Bridge Engineering, 14(2), 158-177. https://doi.org/10.7250/bjrbe.2019-14.438

Dasović, B., Galić, M., \& Klanšek, U. (2019) Active BIM Approach to Optimize Work Facilities and Tower Crane Locations on Construction Sites With Repetitive Operations. Buildings, 9, 21.

https://doi.org/10.3390/buildings 9010021

Dell'Acqua, G., Guerra de Oliveira, S., \& Biancardo, S. A. (2018). Railway-BIM: Analytical Review, Data Standard and Overall Perspective. Ingegneria Ferroviaria, 73(11), 901-923.

Department for Business, Energy and Industrial Strategy. (2017). Industrial Strategy: building a Britain fit for the future. Great Britain. Retrieved from https://www.timeshighereducation.com/sites/default/files/breaking news_files/industrial-strategy-white-paper.pdf [Accessed 9 October 2019].

EU BIM. (2017). Handbook for the Introduction of Building Information Modelling by the European Public Sector. Strategic Action for Construction Sector Performance: Driving Value, Innovation and Growth. [Online] Retrieved from http://www.eubim.eu/downloads/EU_BIM_Task_Group_Handbook_FINAL. PDF [Accessed 9 October 2019].

Fanning, B., Clevenger, C. M., Ozbek, M. E., \& Mahmoud, H. (2015). Implementing BIM on Infrastructure: Comparison of Two Bridge Construction Projects. Practice periodical on structural design and construction, 20(4), 04014044. https://doi.org/10.1061/(ASCE)SC.1943-5576.0000239

Galić, M., Venkrbec, V., Chmelik, F., Feine, I., Pučko, Z.; \& Klanšek, U. (2017). Survey of Accomplishments in BIM Implementation in Croatia, the Czech Republic, Germany, and Slovenia. E-GFOS, 8(15), 23-35.

https://doi.org/10.13167/2017.15.3 
Ghaffarianhoseini, A., Tookey, J., Ghaffarianhoseini, A., Naismith, N., Azhar, S., Efimova, O., \& Raahemifar, K. (2017). Building Information Modelling (BIM) Uptake: Clear Benefits, Understanding Its Implementation, Risks and Challenges. Renewable and Sustainable Energy Reviews, 75, 1046-1053. https://doi.org/10.1016/j.rser.2016.11.083

Gholizadeh, P., Esmaeili, B., \& Goodrum, P. (2018) Diffusion of Building Information Modeling Functions in the Construction Industry. Journal of Management in Engineering, 34, 04017060.

https://doi.org/10.1061/(asce)me.1943-5479.0000589

Habibzadeh, H., Kaptan, C., Soyata, T., Kantarci, B., \& Boukerche, A. (2019). Smart City System Design: A Comprehensive Study of the Application and Data Planes. ACM Computing Surveys (CSUR), 52(2), 1-38.

https://doi.org/10.1145/3309545

Hosseini, M. R., Maghrebi, M., Akbarnezhad, A., Martek, I., \& Arashpour, M. (2018). Analysis of Citation Networks in Building Information Modeling Research. Journal of Construction Engineering and Management, 144, 04018064. https://doi.org/10.1061/(asce)co.1943-7862.0001492

Jackson, Ph. (2019). Nordic Study of Classification Systems for Infrastructure \& Transportation. Version S2. [Online]. Retrieved from https://buildingsmart. fi/wp-content/uploads/2019/12/20191021-Nordic-Study-S2_FINAL.pdf [Accessed 9 October 2019].

Jalaei, F., \& Jrade, A. (2015). Integrating Building Information Modeling (BIM) and LEED System at the Conceptual Design Stage of Sustainable Buildings. Sustainable Cities and Society, 18, 95-105.

https://doi.org/10.1016/j.scs.2015.06.007

Jones, S. A., Laquidara-Carr, D., Lorenz, A., Buckley, B., \& Barnett, S. (2017). The Business Value of BIM for Infrastructure 2017. Bedford, MA, USA: Dodge Data \& Analytics. [Online]. Retrieved from https://www2.deloitte.com/content/ dam/Deloitte/us/Documents/finance/us-fas-bim-infrastructure.pdf [Accessed 9 October 2019].

Krystallis, I., Papadonikolaki, E., Iuorio, O., \& Locatelli, G. (2019). Towards a Methodology for Quantifying the Benefits of BIM. In Proceedings of 2019 European Conference on Computing in Construction (EC3). European Council on Computing in Construction (EC3). https://doi.org/10.35490/EC3.2019.138

Kumar, H., Singh, M. K., Gupta, M. P., \& Madaan, J. (2020). Moving Towards Smart Cities: Solutions that Lead to the Smart City Transformation Framework. Technological forecasting and social change, 153, 119281.

https://doi.org/10.1016/j.techfore.2018.04.024

Lee, M. Oh, J., Lee, J., Hong, S. W., \& Jeong, Y. (2015). Integrated System for BIM-Based Collaborative Design. Automation in Construction, 58, 196-206. https://doi.org/10.1016/j.autcon.2015.07.015

Liu, Y., van Nederveen, S., Wu, C., \& Hertogh, M. (2018). Sustainable Infrastructure Design Framework Through Integration of Rating Systems and Building Information Modeling. Advances in Civil Engineering, 13, 10. https://doi.org/10.1155/2018/8183536 
Love, P. E. D., Liu, J., Matthews, J., Sing C. P., \& Smith, J. (2015). Future Proofing PPPs: Life-Cycle Performance Measurement and Building Information Modelling. Automation in Construction, 56, 26-35. https://doi.org/10.1016/j.autcon.2015.04.008

Lu, Q., Won, J., \& Cheng, J. C. P. (2016). A Financial Decision Making Framework for Construction Projects Based on 5D Building International Modeling (BIM). Journal of Project Management, 34, 3-21. https://doi.org/10.1016/j.ijproman.2015.09.004

Mahamadu, A. M., Mahdjoubi, L., Booth, C., Manu, P., \& Manu, E. (2019). Building Information Modelling (BIM) Capability and Delivery Success on Construction Projects. Construction Innovation, 19(2), 170-192. https://doi.org/10.1108/CI-03-2018-0016

Marzouk, M., \& Hisham, M. (2014). Implementing Earned Value Management Using Bridge Information Modeling. KSCE Journal of Civil Engineering, 18(5), 1302-1313. https://doi.org/10.1007/s12205-014-0455-9

McArthur, L. J. (2015). A Building Information Management (BIM) Framework and Supporting Case Study for Existing Building Operations, Maintenance and Sustainability. Procedia Engineering, 118, 1104-1111. https://doi.org/10.1016/j.proeng.2015.08.450

Oxford Dictionary. (n. d.). Definition of infrastructure. [Online]. Retrieved from https://languages.oup.com/ [Accessed 19 November 2019].

Poirier, E. A., French, S. S., \& Forgues, D. (2015). Measuring the Impact of BIM on Labor Productivity in a Small Specialty Contracting Enterprise Through Action-Research. Automation in Construction, 58, 74-84. https://doi.org/10.1016/j.autcon.2015.07.002

Sanchez, A. (2016). Delivering Value With BIM: A Framework for Built Environment Practitioners. In Conference: The CIB World Building Congress (vol. 3, pp. 272-283). Finland, Tampere.

Sanchez, A., Kraatz, J. A., Hampson, K. D., \& Loganathan, S. (2014). BIM for Sustainable Whole-of-Life Transport Infrastructure Asset Management. In Sustainability in Public Works Conference, 27-29 July 2014.

Shou, W., Wang, J., Wang, X., \& Chong, H. Y. (2015). A Comparative Review of Building Information Modelling Implementation in Building and Infrastructure Industries. Archives of computational methods in engineering, 22(2), 291-308. https://doi.org/10.1007/s11831-014-9125-9

Succar, B., \& Kassem, M. (2015). Macro-BIM Adoption: Conceptual Structures. Automation in Construction, 57, 64-79. https://doi.org/10.1016/j.autcon.2015.04.018

Vilutiene, T., Kalibatiene, D., Hosseini, M. R., Pellicer, E., \& Zavadskas, E. K. (2019). Building Information Modeling (BIM) for Structural Engineering: A Bibliometric Analysis of the Literature. Advances in Civil Engineering, 1-19. https://doi.org/10.1155/2019/5290690

Volk, R., Stengel, J., \& Schultmann, F. (2014). Building Information Modeling (BIM) for Existing Buildings - Literature Review and Future Needs. Automation in construction, 38, 109-127.

https://doi.org/10.1016/j.autcon.2013.10.023 
Waltman, L., \& Van Eck, N. J. (2013). A Smart Local Moving Algorithm for Large-Scale Modularity-Based Community Detection. The European physical journal B, 86(11), 471. https://doi.org/10.1140/epjb/e2013-40829-0

Wang, J., Wang, X., Wang, W., Chong, S. H. Y., \& Guo, J. (2016). Building Information Modeling-Based Intregration of MEP Layout Designs and Constructability. Automation in Construction, 61, 134-146. https://doi.org/10.1016/j.autcon.2015.10.003

Williams, B., Haines, B., Roper, K., \& Yang, E. (2019). Building Information Modelling (BIM) for Facility Management (FM): Industry Survey of Building Assets. Journal of Facility Management Education and Research, 3(1), 18-26. https://doi.org/10.22361/jfmer/112195

Yang, J. B., \& Chou, H. Y. (2019). Subjective Benefit Evaluation Model for Immature BIM-Enabled Stakeholders. Automation in Construction, 106, 102908. https://doi.org/10.1016/j.autcon.2019.102908

Yilmaz, G., Akcamete, A., \& Demirors, O. (2019). A Reference Model for BIM Capability Assessments. Automation in Construction, 101, 245-263. https//doi.org/10.1016/j.autcon.2018.10.022

Zhang, S., Sulankivi, K., Kiviniemi, M., Romo, I., Eastman C. M., \& Teizer, J. (2015). BIM-Based Fall Hazard Identification and Prevention In Construction Safety Planning. Safety science, 72, 31-45. https://doi.org/10.1016/j.ssci.2014.08.001 